\title{
Experience during early adulthood shapes the learning capacities and the number of synaptic boutons in the mushroom bodies of honey bees (Apis mellifera)
}

\author{
Amélie Cabirol, ${ }^{1,2}$ Rufus Brooks, ${ }^{1}$ Claudia Groh, ${ }^{3}$ Andrew B. Barron, ${ }^{2}$ \\ and Jean-Marc Devaud ${ }^{1}$ \\ ${ }^{1}$ Center for Integrative Biology (CBI), Toulouse University, CNRS, UPS, Toulouse 31062 France; ${ }^{2}$ Department of Biological Sciences, \\ Macquarie University, North Ryde, New South Wales 2109, Australia; ${ }^{3}$ Department of Behavioral Physiology and Sociobiology, \\ University of Würzburg, Biozentrum, Am Hubland, 97074 Würzburg, Germany
}

\begin{abstract}
The honey bee mushroom bodies (MBs) are brain centers required for specific learning tasks. Here, we show that environmental conditions experienced as young adults affect the maturation of MB neuropil and performance in a MB-dependent learning task. Specifically, olfactory reversal learning was selectively impaired following early exposure to an impoverished environment lacking some of the sensory and social interactions present in the hive. In parallel, the overall number of synaptic boutons increased within the $\mathrm{MB}$ olfactory neuropil, whose volume remained unaffected. This suggests that experience of the rich in-hive environment promotes $\mathrm{MB}$ maturation and the development of MB-dependent learning capacities.
\end{abstract}

[Supplemental material is available for this article.]

Experience that individuals acquire continuously influences their brain architecture and function, and ultimately their behavior (Kolb and Gibb 2013). For instance, rats exposed to enriched environments (providing rich sensorimotor and social experience) at early stages of life exhibit changes in neural architecture and function in brain parts involved in learning and memory (Eckert and Abraham 2013). Similar changes have been reported in other species, including invertebrates (Withers et al. 1993; Heisenberg et al. 1995; Fahrbach et al. 1998; Dickel et al. 2000; Dobrin et al. 2011; Simpson and Kelly 2011; Mallory et al. 2016). Surprisingly, how early living conditions affect learning performance is poorly known in a main insect model for the study of learning: the honeybee (Apis mellifera). Yet, it displays remarkable behavioral plasticity as it experiences multiple sensory and social stimuli during its lifetime. Importantly, its brain also displays remarkable experience-dependent plasticity (Withers et al. 1993; Fahrbach et al. 1998; Hourcade et al. 2009, 2010). Here we tackle the question of whether exposure to specific environmental conditions during early adulthood influences learning performance, and how this might relate to brain maturation in honeybees, using the possibility to easily manipulate their naturally rich environment.

Honeybees emerge into adult life inside a colony providing many social and sensory stimuli, particularly olfactory ones. Based on an age-related polyethism, young workers first perform in-hive tasks before foraging outdoors when older (Robinson 1992). Foraging requires the acquisition of different skills to enable the efficient navigation between multiple food sources and to return back to the hive, as well as learning the variable value of food sources over time (Giurfa 2013; Klein et al. 2017). The development of such learning skills is likely to involve a maturation process within the underlying brain circuits. Such maturation is especially apparent in the mushroom bodies (MBs), multisensory

Corresponding author: jean-marc.devaud@univ-tlse3.fr, amelie. cabirol@univ-tlse3.fr

Article is online at http://www.learnmem.org/cgi/doi/10.1101//m.045492.117. integration centers important for learning and memory (Erber et al. 1980; Strausfeld et al. 1998; Menzel 1999; Gronenberg 2001). The volumes of both the lip and collar (different MB neuropils receiving respectively olfactory and visual input) increase during the first week of adulthood, regardless of exposure to a normally rich environment (the hive) or to sensory and social deprivation (Fahrbach et al. 1998; Muenz et al. 2015). Thus, part of the age-related volume expansion undergone by the MBs is programmed and experience-independent (Fahrbach et al. 1998), while experience of the hive environment drives an additional growth (Withers et al. 1993). Surprisingly, very little is known about the functional implications of such $\mathrm{MB}$ maturation, and about the roles of these two components of MB plasticity. Is the minimal developmental program occurring in impoverished conditions sufficient to support efficient learning in young adults? Here, we asked whether environmental conditions, at an age when adult $\mathrm{MB}$ maturation occurs, influence the development of MB-dependent learning performance.

The formation of olfactory memories in bees is accompanied by functional and structural plasticity within the MBs (Szyszka et al. 2008; Hourcade et al. 2010). Yet, MB function appears to be dispensable during the initial acquisition of unambiguous odor-reward associations (Malun et al. 2002; Giurfa 2003), while it is required in ambiguous tasks (Devaud et al. 2007, 2015), as shown using the classical olfactory conditioning of the proboscis extension response (PER) (Bitterman et al. 1983; Giurfa and Sandoz 2012). The PER is evoked by presenting sucrose to the animal's antennae, and can also be triggered by an odorant previously associated with the sucrose reward. In a complex task such as reversal learning, bees are trained first to respond to an odor A reinforced

2017 Cabirol et al. This article is distributed exclusively by Cold Spring Harbor Laboratory Press for the first 12 months after the full-issue publication date (see http://learnmem.cshlp.org/site/misc/terms.xhtml). After 12 months, it is available under a Creative Commons License (Attribution-NonCommercial 4.0 International), as described at http://creativecommons.org/licenses/by-nc/ $4.0 \%$. 
with sucrose and not to a non-rewarded odor B (A+ versus B-) and, in a second phase, to do the reverse (A- versus $B+$ ). Several studies showed that bees can solve the temporal ambiguity introduced by changing the association contingencies between the two phases (Komischke et al. 2002; Hadar and Menzel 2010; Mota and Giurfa 2010). In addition, this resolution requires full function of MB neural subcircuits (Devaud et al. 2007; Boitard et al. 2015). We thus assessed the performance of 10 -d-old bees in reversal learning, after they had been exposed to either their natural environment or to artificially impoverished conditions, and searched for anatomical evidence of an influence of early experience on $\mathrm{MB}$ maturation. Our results indicate that early sensory experience is indeed involved in shaping MB maturation and MB-dependent learning performance.

We first investigated whether early experience received in the hive could influence learning performance in a MB-dependent task. For this, 10-d-old bees were trained in a reversal learning task following exposure to either normal conditions (in-hive group) or impoverished conditions in which sensory (olfactory, visual) stimuli as well as social interactions were reduced (impoverished group: 15 bees in a cage maintained in an incubator, 2 cages per incubator) (Fig. 1). These different conditions had no significant impact on learning during the first phase of olfactory conditioning (RM-ANOVA: Group effect $\left.F_{(2,77)}=1.14, P=0.3349\right)$. Consistently, both groups learned to respond more to $\mathrm{A}+$ than to $\mathrm{B}-$ across trials (Fig. 1A,B left) (Trial $\times$ Odorant interaction: in-hive: $F_{(4,39)}=17,06, P$ $<0.0001$; impoverished: $\left.F_{(1,39)}=15,46, P<0.0001\right)$. By the end of this first conditioning phase, bees responded significantly more to A+ than to B- in both groups (Tukey's HSD post hoc analysis on the last trial; $P<0.001$ in both cases). In contrast, performance differed markedly between groups in the second (reversal) phase. In-hive bees progressively changed their responses to the stimuli (Trial $\times$ Odorant interaction: $\left.F_{(4,39)}=21.68, P<0.0001\right)$ and finally responded more frequently to $\mathrm{B}$ than to $\mathrm{A}$ in the last trial $(P<$ 0.05 ) (Fig. 1A, right), thus showing the ability to reverse the previ- ously learned contingency. Although bees from the impoverished group did change their response patterns (Trial $\times$ Odorant interaction: $\left.F_{(4,39)}=9.35, P<0.0001\right)$, they responded equally frequently to either odorant at the fifth trial $(P=1)$ (Fig. 1B, right). Importantly, reversal learning differences between impoverished and in-hive bees was not due to a putative impact of environmental conditions on sucrose responsiveness (Supplemental Fig. S1). Thus, exposure to some aspects of the in-hive environment missing in the impoverished conditions enhances performance in the reversal learning task at $10 \mathrm{~d}$ of age.

If the detrimental effect of an impoverished environment were not a general impairment of learning, but rather an impairment of complex tasks such as reversal learning, we predicted that it should not affect performance in a simpler task. We thus trained 10-d-old bees of both groups to perform two consecutive differential conditioning using independent odorants (A+ versus B-, then C+ versus D-) (Fig. 2), a control task similar to reversal learning but whose second phase involves no ambiguity resolution (Devaud et al. 2007). As expected, no significant difference between the groups was observed in the first phase $\left(F_{(2,80)}=0.72\right.$, $P=0.5761$, which was identical to that of reversal learning, where no treatment effect had been found: both groups discriminated the two stimuli (Odorant effect: in-hive: $F_{(1,46)}=22.95, P<0.0001 ; \mathrm{im}$ poverished: $\left.F_{(1,35)}=5.78, P<0.0001\right)$ and responded more to the rewarded odor in the end $(P<0.001$ in both cases). More important, bees from both groups also performed equally well in the second phase $\left(F_{(2,80)}=0.68 ; P=0.6030\right)$, as they responded more to $\mathrm{C}+$ than to $\mathrm{D}-$ in the last trial $(P<0.001$ in both cases) (Fig. $2 \mathrm{~A}, \mathrm{~B})$. This contrasts strongly with the successful acquisition of the second phase of reversal learning by the in-hive group only. We thus conclude that, in our conditions, the impoverished environment specifically impacted reversal learning.

As the ability to solve reversal learning requires intact function of the MBs (Malun et al. 2002; Devaud et al. 2007), we then asked whether the detrimental effect of impoverished conditions on performance might be correlated with changes in the MB maturation process. To do so, brains of 10 -d-old un-

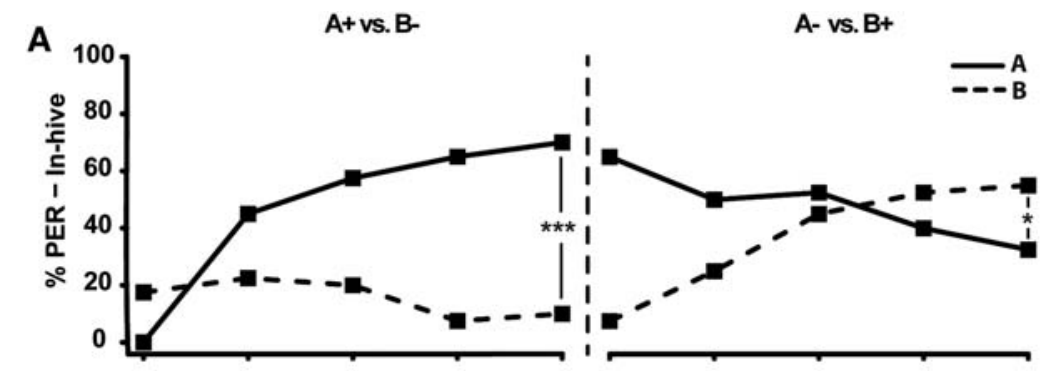

B

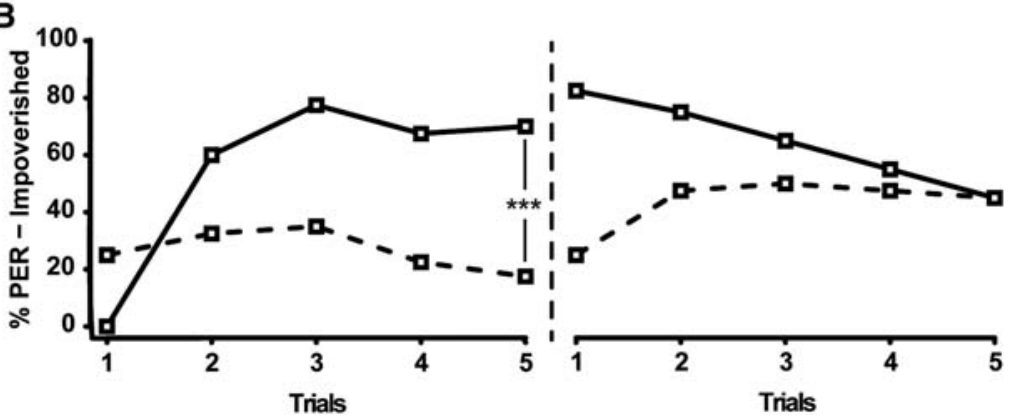

Figure 1. Reversal learning performances of 10 -d-old bees from the in-hive $[N=40,(A)]$ or impoverished environment $[N=40,(B)]$. The percentage of proboscis extension responses (PER) elicited by odor $A$ (solid line) and $B$ (dashed line) is represented during the first phase $(A+B-)$ and the second phase $(A-B$ + ) of the learning task. The odors used as $A$ and $B$ were alternated between the bees and the role of each odor as $A$ or $B$ had no effect on learning (repeated-measures ANOVA: $F=1.41 ; P=0.23$ ). $\left.{ }^{\star \star \star}\right) P<0.001$; $\left({ }^{*}\right) P<0.05$. trained bees from both conditions were collected and immunolabeled with an anti-synapsin antibody to visualize and measure the volumes of the olfactory and visual $\mathrm{MB}$ neuropils (resp. lip and dense collar of the medial calyx), and to count synapsin-positive boutons therein (each bouton being the presynaptic site of an individual microglomerulus, the synaptic unit of the MB neuropile; it corresponds to the axon terminal of the projection neuron contacting dendrites of MB neurons) (Fig. 3A; Supplemental Methods). The use of this nonspecific synaptic marker allowed us to look for general changes in the circuit without focusing on a particular type of synapse (e.g., excitatory or inhibitory) at this stage. We included 1-d-old bees as controls to verify whether, in our conditions, we could observe the reported age-related maturation (Fahrbach et al. 1998; Muenz et al. 2015). It should be noted that all measurements revealed values similar to those published in the literature in the same areas and at similar ages (Groh et al. 2012; Muenz et al. 2015). Volume measurements (Fig. 3B) revealed 


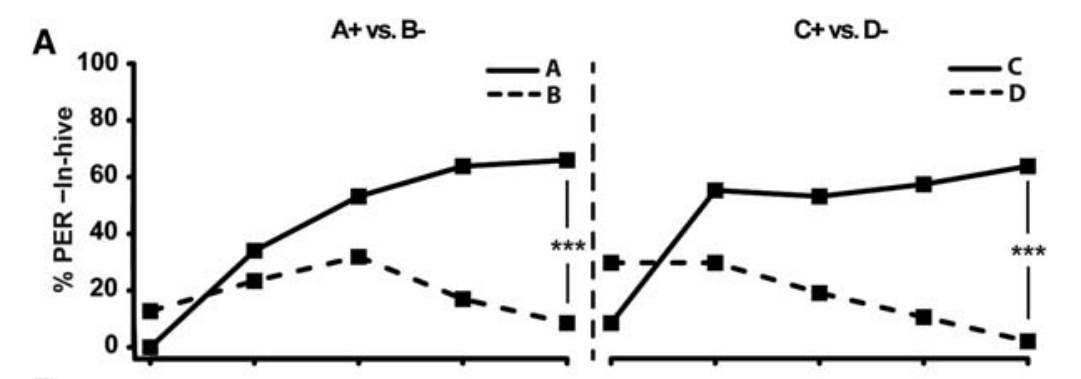

B

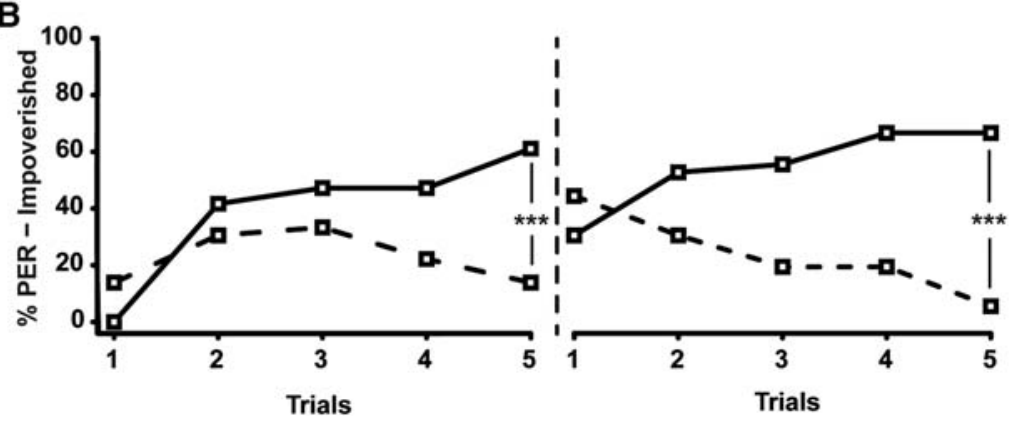

Figure 2. Performances in two consecutive differential conditioning of bees from the in-hive $[N=47$, (A)] or impoverished environment $[N=36,(B)]$. The percentage of PER elicited by odor $A$ (solid line) and $B$ (dashed line) during the first phase $(A+B-)$ and to odors $C$ (solid line) and $D$ (dashed line) during the second phase $(C+D-)$ is represented. The odors used as $A$ and $B(A)$, and $C$ and $D(B)$, were alternated between the bees and the role of each odor as $A$ or $B$, and $C$ or $D$, had no effect on learning $(A / B: F=$ 1.78; $\left.P=0.14 ; C / D: F=0.30 ; P=0.84) .{ }^{* * *}\right) P<0.001$.

variations between the three groups in both neuropils (Kruskal-Wallis $H$-test; lip: $P<0.05$; dense collar: $P<0.05)$. As expected, this difference was due to an age-related expansion of the MBs (Fig. 3B), since overall the medial calyces of 10-d-old bees showed larger volumes than in 1-d-old bees, though this increase did not reach significance level in the lip of in-hive bees (Mann-Whitney $U$-test: lip, impoverished: $U=0 ; P<0.001$; in-hive: $U=27, P=0.0952$; collar, impoverished: $U$ $=11 ; P<0.05$; in-hive: $U=22.5 ; P<0.05$ ). However, volumes of the lip and dense collar in 10-d-old bees were not impacted by environmental conditions (lip: $U=37$; $P=0.2721$; dense collar: $U=32, \quad P=$ 0.6070). Yet, the lip volume seemed more variable between individuals within the in-hive group than within the impoverished group. In addition, synaptic bouton density, measured in defined cubic sampling volumes $\left(1000 \mu^{3}\right)$ within the MB lip and dense collar, did not vary across all groups for either region (Kruskal-Wallis $H$-test; lip: $P=0.2235$; dense collar: $P=0.2673$ ), thus revealing no clear relationship with age or living conditions (Fig. 3C). In a next step, following previous studies (Groh et al. 2012; Muenz et al. 2015), we combined the volume of each $\mathrm{MB}$ subregion and the density of synaptic boutons therein, in order to extrapolate the overall number of synaptic boutons within each of these regions of the $\mathrm{MB}$ medial calyx
A
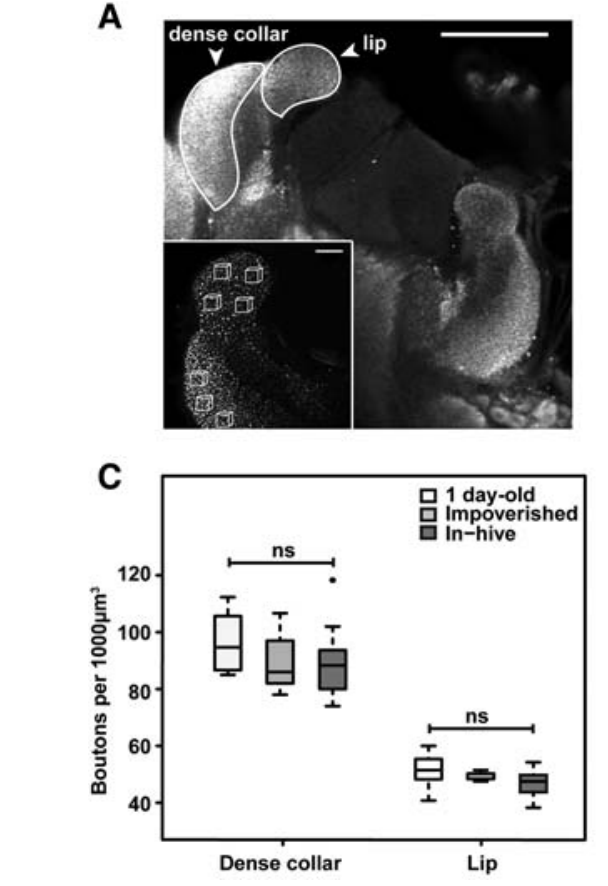

(Supplemental Methods). The resulting estimations revealed a clear effect of environmental conditions on synaptic bouton numbers within the lip subregion of the calyx (Fig. 3D). Indeed, the extrapolated total number of synaptic boutons per lip was significantly higher in bees from the impoverished group than from the in-hive group $(U=52, \quad P<0.005)$. Values for the impoverished group also differed from that of 1 -d-old bees $(U=8$, $P<0.05)$, unlike in-hive bees $(U=44, P=$ $0.4807)$. This markedly higher number of boutons in the lip of impoverished bees appears to be caused by different intra-individual correlations between region volume and bouton density: positive in the impoverished group (Spearman correlation; $\rho=0.8117, P<0.05)$ and negative in the in-hive group ( $\rho=-0.9500, P$ $<0.0005)$. In contrast, there was no correlation in 1-d-old bees. Hence, MB maturation during early adulthood was clearly affected by living in an impoverished environment. Since the total number of boutons within the dense collar did not vary between groups (Kruskal-Wallis $H$-test; $P=0.6454)$ and showed no intraindividual correlation, the impact of environmental conditions was specific to
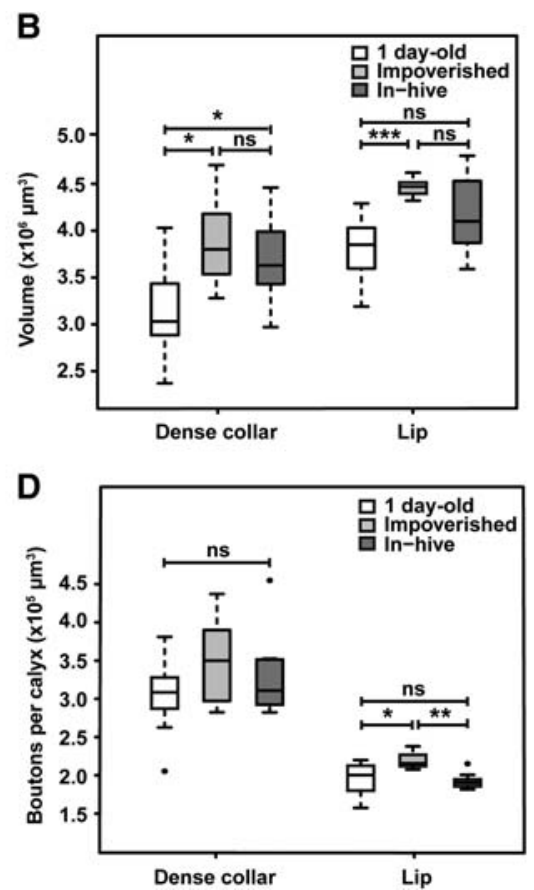

Figure 3. Structural analyses of the $M B$ of 1 -d-old bees $[N=11]$ and 10 -d-old bees from the in-hive $[N$ $=9]$ or impoverished $[N=7]$ environment. $(A)$ Single frontal confocal section of a central region of the right medial calyx immunolabeled for synapsin, revealing the presynaptic terminals that are part of the $\mathrm{MB}$ microglomeruli (scale bar is $100 \mu \mathrm{m}$ ). Inset: enlarged view of the lip and collar (scale bar is $20 \mu \mathrm{m}$ ). Synaptic boutons were counted in boxes of $1000 \mu \mathrm{m}^{3}$ (four boxes in the lip, three in the dense collar). $(B-D)$ Boxplots of the volume of the lip and dense collar of the MB right median calyx $(B)$, the number of synaptic boutons per $1000 \mathrm{\mu m}^{3}(C)$ and the number of synaptic boutons normalized to the volume of each neuropil compartment (lip or dense collar) of the medial calyx $(D)$. The sample size of each group is displayed under the corresponding boxplot. $\left(^{* \star *}\right) P<0.0005 ;\left(^{* *}\right) P<0.005 ;\left(^{*}\right) P<0.05$. 
the olfactory neuropil, thus in keeping with the effect on MB-dependent olfactory learning.

It has been proposed that part of the age-related MB maturation process occurring during early adulthood in the hive prepares the brain for foraging outside the hive ("experience-expectant plasticity": Fahrbach et al. 1998). Here, impoverished conditions led to an impairment of reversal learning, an example of highly elaborate learning skills related to foraging outside the hive (Giurfa 2013; Klein et al. 2017). This suggests that early experience is important for developing optimal learning performance useful for foraging. Yet, experience of appropriate environmental conditions at later ages might be sufficient to promote or restore such repertoire. Future work should help to identify whether the promotion of reversal learning by environmental conditions depends on a critical period

Nevertheless, a striking result of this study is the task-specific impact of early experience: bees reared in the impoverished environment could not achieve reversal learning but were perfectly able to solve two consecutive differential conditionings. Thus, our manipulation of early environment did not prevent bees from learning new odor-food associations, but rather to update their responses as such associations change over time, which corresponds to a higher level of complexity. Reversal learning is expected to share common neural circuits with differential conditioning (particularly the olfactory antennal lobes whose general role in olfactory learning is well established), but it requires functional MBs, which are dispensable for the acquisition of nonambiguous associations during differential conditioning (Malun et al. 2002; Giurfa 2003; Devaud et al. 2007). Thus, we considered whether changes in the $\mathrm{MB}$ architecture could be part of a potential mechanism for the specific effect of early experience on MB-dependent learning performance. Yet, we cannot discard the possibility that changes affecting other brain regions may contribute to this effect. Environmental manipulation did not seem to impact the age-related volume expansion of neuropils, which is attributed to the progressive dendritic branching process occurring in adults (Farris et al. 2001; Groh et al. 2012; Muenz et al. 2015). The inter-individual variability in the lip volume was however more pronounced in in-hive bees than in bees from the impoverished group, suggesting that olfactory experiences were more diverse in the hive. In parallel, the number of synaptic boutons in the lip was shown to decrease with age in undisturbed conditions, thus suggesting pruning of some of those initially established (Muenz et al. 2015). Because this decrease is not apparent before the end of the first week, it is likely that both addition of new synapses and pruning occur initially. Consistent with this interpretation, here the estimated total number of synaptic boutons in the lip of 10-d-old in-hive bees did not differ from that of 1-d-old bees. More important, 10-d-old bees from the impoverished group had more boutons than in-hive bees, thus suggesting that, under impoverished conditions, the initial addition of boutons to the lip was effective, but that the plasticity leading to pruning was impaired. This is also supported by the finding that the lip volume and bouton density were correlated in opposite ways in impoverished and in-hive groups. Therefore, we conclude that the maturation of the lip architecture combines its programmed expansion as dendrites grow and synapses are formed initially, together with a pruning process that presumably would enable plastic shaping of the network in an activity-dependent manner. This model is consistent with previous observations of experience-dependent pruning of boutons in the collar following exposure to light, both in bees and ants (Stieb et al. 2010; Scholl et al. 2014; Yilmaz et al. 2016). More recently, an elegant study showed that leaf-cutting ants restricted to collect only one plant species displayed more synaptic boutons than controls in their lips, thus suggesting that synaptic pruning is lower in impoverished conditions (Falibene et al. 2015).
What might be the underlying mechanism of experiencedependent MB maturation in young adult bees? Future work is needed to address this question, but a general feature of how environmental enrichment affects brain circuits is a shift in the excitation/inhibition balance (Caroni et al. 2012; Griffen and Maffei 2014), and the variety of synaptic profiles within the MB microglomeruli (not revealed by our immunolabeling restricted to synaptic sites from projection neurons) suggests functional diversity (Ganeshina and Menzel 2001; Groh et al. 2012). At the moment, we cannot distinguish between the contributions of excitatory and inhibitory synapses to the changes induced by environmental manipulation, but interestingly, achieving olfactory reversal learning relies on a sufficient level of GABA-mediated inhibition to the MB network in both honeybees and fruit flies (Wu et al. 2012; Boitard et al. 2015). This may be a more general rule, as GABA also plays an important role in visual or spatial versions of reversal learning (Morellini et al. 2010; Ren et al. 2012; Hausrat et al. 2015). A possibility might be that GABAergic neurons undergo activity-dependent changes during early adulthood to provide functional inhibition to the MBs at $10 \mathrm{~d}$. In impoverished conditions, such changes in GABAergic connections might be disturbed, due to reduced olfactory stimulations, but possibly also as a consequence of stress induced by partial social isolation, since brain deficits in GABA have been associated with stressful states in various species (Bailey and Nutt 2008; Fossat et al. 2014; Goddard 2016; Mohammad et al. 2016). Indeed, young rats reared in isolation exhibited a deficit in GABAergic neurons associated with impaired reversal learning (Powell et al. 2015). However, because only the maturation of the lip is affected, a difference in the variety and/or diversity of olfactory stimulations is more likely to be a cause for the poor learning performance of the impoverished group.

Hence, we propose that one of the reasons why an impoverished environment impairs the capacity for reversal learning is that it affects the maturation of the lip synaptic architecture. Effective reversal of learning implies that a learned neural activity pattern driving a specific behavioral response to one odorant (e.g., PER to $\mathrm{A}+$ ) can be functionally replaced by a new pattern driving a new response at the end of conditioning (i.e. no PER to A-). Models of olfactory learning in insects propose that it depends on plastic changes in connection weights between Kenyon cells (KCs, the MB neurons) and input and output neurons, including inhibitory ones (Finelli et al. 2008; Smith et al. 2008; Chen et al. 2015). These models are supported by studies showing learningrelated changes in the activity of these neuron populations (Szyszka et al. 2008; Strube-Bloss et al. 2011; Menzel 2014; Hige et al. 2015). Therefore we propose that the altered MB structure and learning performances seen in bees from the impoverished environment are functionally related. Although this hypothesis is speculative currently, it illustrates the possibility to encompass the existing data in an integrated model explaining how an incomplete maturation of specific aspects of MB connectivity might lead to a selective impairment of reversal learning.

As a final note, the naturally rich environment of the hive allowed us to compare cognitive and brain maturation in both normal and impoverished conditions. This is in contrast with a large part of the literature on the effects of environmental enrichment, where animals were studied outside of their natural context, in laboratory rearing conditions corresponding rather to impoverished environments (Rosenzweig and Bennett 1996). Hence, we would like to stress the importance of considering the impact of ecological conditions on how the brain and behavior of animals mature, in line with recent vertebrate studies highlighting the differences between naturalistic environments and artificially enriched environments in cognitive neuroscience (Landers et al. 2011; Schaefers 2013; Bardi et al. 2016; Lambert et al. 2016). Within this 
framework, to our knowledge this is the first demonstration that natural conditions are important for the proper maturation of learning performances and their underlying neural networks in an invertebrate model.

\section{Acknowledgments}

We thank Lucie Hotier for beekeeping and technical assistance, and Prof. Wolfgang Roessler for hosting AC in his laboratory (Department of Behavioral Physiology and Sociobiology at the University of Würzburg) and enabling her to get trained into neurohistochemical techniques and analyses. We also thank the CNRS, the Université Paul Sabatier and Macquarie University.

\section{References}

Bailey JE, Nutt DJ. 2008. GABA-A receptors and the response to $\mathrm{CO}_{2}$ inhalation - A translational trans-species model of anxiety? Pharmacol Biochem Behav 90: 51-57.

Bardi M, Kaufman C, Franssen C, Hyer MM, Rzucidlo A, Brown M, Tschirhart M, Lambert KG. 2016. Paper or Plastic? Exploring the effects of natural enrichment on behavioural and neuroendocrine responses in Long-Evans rats. J Neuroendocrinol 28. doi: 10.1111/jne.12383.

Bitterman ME, Menzel R, Fietz A, Schäfer S. 1983. Classical conditioning of Proboscis Extension in Honeybees (Apis mellifera). J Comp Psychol 97: 107-119.

Boitard C, Devaud J-M, Isabel G, Giurfa M. 2015. GABAergic feedback signaling into the calyces of the mushroom bodies enables olfactory reversal learning in honey bees. Front Behav Neurosci 9: 198.

Caroni P, Donato F, Muller D. 2012. Structural plasticity upon learning: regulation and functions. Nat Rev Neurosci 13: 478-490.

Chen J-Y, Marachlian E, Assisi C, Huerta R, Smith BH, Locatelli F, Bazhenov M. 2015. Learning modifies odor mixture processing to improve detection of relevant components. J Neurosci 35: 179-197.

Devaud J-M, Blunk A, Podufall J, Giurfa M, Grünewald B. 2007. Using local anaesthetics to block neuronal activity and map specific learning tasks to the mushroom bodies of an insect brain. Eur J Neurosci 26: 3193-3206.

Devaud J-M, Papouin T, Carcaud J, Sandoz J, Grünewald B, Giurfa M. 2015. Neural substrate for higher-order learning in an insect: mushroom bodies are necessary for configural discriminations. Proc Natl Acad Sci 112: E5854-E5862.

Dickel L, Boal JG, Budelmann BU. 2000. The effect of early experience on learning and memory in cuttlefish. Dev Psychobiol 36: 101-110.

Dobrin SE, Herlihy JD, Robinson GE, Fahrbach SE. 2011. Muscarinic regulation of Kenyon cell dendritic arborizations in adult worker honey bees. Arthropod Struct Dev 40: 409-419.

Eckert MJ, Abraham WC. 2013. Effects of environmental enrichment exposure on synaptic transmission and plasticity in the hippocampus. Curr Top Behav Neurosci 15: 165-187.

Erber J, Masuhr T, Menzel R. 1980. Localization of short-term memory in the brain of the bee, Apis rnellifera. Physiol Entomol 5: 343-358.

Fahrbach SE, Moore D, Capaldi EA, Farris SM, Robinson GE. 1998. Experience-expectant plasticity in the mushroom bodies of the honeybee. Learn Mem 5: 115-123.

Falibene A, Roces F, Rössler W. 2015. Long-term avoidance memory formation is associated with a transient increase in mushroom body synaptic complexes in leaf-cutting ants. Front Behav Neurosci 9: 84.

Farris SM, Robinson GE, Fahrbach SE. 2001. Experience- and age-related outgrowth of intrinsic neurons in the mushroom bodies of the adult worker honeybee. J Neurosci 21: 6395-6404.

Finelli LA, Haney S, Bazhenov M, Stopfer M, Sejnowski TJ. 2008. Synaptic learning rules and sparse coding in a model sensory system. PLoS Comput Biol 4: e1000062.

Fossat P, Bacqué-Cazenave J, De Deurwaerdère P, Delbecque J, Cattaert D. 2014. Anxiety-like behavior in crayfish is controlled by serotonin. Science 344: 1293-1297.

Ganeshina O, Menzel R. 2001. GABA-immunoreactive neurons in the mushroom bodies of the honeybee: An electron microscopic study. $J$ Comp Neurol 437: 335-349.

Giurfa M. 2003. Cognitive neuroethology: dissecting non-elemental learning in a honeybee brain. Curr Opin Neurobiol 13: 726-735.

Giurfa M. 2013. Cognition with few neurons: Higher-order learning in insects. Trends Neurosci 36: 285-294.

Giurfa M, Sandoz J-C. 2012. Invertebrate learning and memory: fifty years of olfactory conditioning of the proboscis extension response in honeybees. Learn Mem 19: 54-66.

Goddard AW. 2016. Cortical and subcortical $\gamma$ amino acid butyric acid deficits in anxiety and stress disorders: clinical implications. World $J$ Psychiatry 6: 43-53.
Griffen TC, Maffei A. 2014. GABAergic synapses: their plasticity and role in sensory cortex. Front Cell Neurosci 8: 91.

Groh C, Lu Z, Meinertzhagen IA, Rössler W. 2012. Age-related plasticity in the synaptic ultrastructure of neurons in the mushroom body calyx of the adult honeybee Apis mellifera. J Comp Neurol 520: 3509-3527.

Gronenberg W. 2001. Subdivisions of hymenopteran mushroom body calyces by their afferent supply. J Comp Neurol 435: 474-489.

Hadar R, Menzel R. 2010. Memory formation in reversal learning of the honeybee. Front Behav Neurosci 4: 186.

Hausrat TJ, Muhia M, Gerrow K, Thomas P, Hirdes W, Tsukita S, Heisler FF, Herich L, Dubroqua S, Breiden P, et al. 2015. Radixin regulates synaptic GABAA receptor density and is essential for reversal learning and short-term memory. Nat Commun 6: 6872.

Heisenberg M, Heusipp M, Wanke C. 1995. Structural plasticity in the Drosophila brain. J Neurosci 15: 1951-1960.

Hige T, Aso Y, Rubin GM, Turner GC. 2015. Plasticity-driven individualization of olfactory coding in mushroom body output neurons. Nature 526: 258-262.

Hourcade B, Perisse E, Devaud J-M, Sandoz J-C. 2009. Long-term memory shapes the primary olfactory center of an insect brain. Learn Mem 16: 607-615.

Hourcade B, Muenz TS, Sandoz J-C, Rössler W, Devaud J-M. 2010. Long-term memory leads to synaptic reorganization in the mushroom bodies: a memory trace in the insect brain? J Neurosci 30: 6461-6465.

Klein S, Cabirol A, Devaud J-M, Barron AB, Lihoreau M. 2017. Why bees are so vulnerable to environmental stressors. Trends Ecol Evol 32: 268-278.

Kolb B, Gibb R. 2013. Searching for the principles of brain plasticity and behavior. Cortex 58: 251-260.

Komischke B, Giurfa M, Lachnit H, Malun D. 2002. Successive olfactory reversal learning in honeybees. Learn Mem 9: 122-129.

Lambert K, Hyer M, Bardi M, Rzucidlo A, Scott S, Terhune-cotter B, Hazelgrove A, Silva I, Kinsley C. 2016. Natural-enriched environments lead to enhanced environmental engagement and altered neurobiological resilience. Neuroscience 330: 386-394.

Landers MS, Knott GW, Lipp HP, Poletaeva I, Welker E. 2011. Synapse formation in adult barrel cortex following naturalistic environmental enrichment. Neuroscience 199: 143-152.

Mallory HS, Howard AF, Weiss MR. 2016. Timing of environmental enrichment affects memory in the house cricket, Acheta domesticus. PLoS One 11: 1-13.

Malun D, Giurfa M, Giovanni Galizia C, Plath N, Brandt R, Gerber B, Eisermann B. 2002. Hydroxyurea-induced partial mushroom body ablation does not affect acquisition and retention of olfactory differential conditioning in honeybees. J Neurobiol 53: 343-360.

Menzel R. 1999. Memory dynamics in the honeybee. J Comp Physiol A 185: 323-340.

Menzel R. 2014. The insect mushroom body, an experience-dependent recoding device. J Physiol Paris 108: 84-95.

Mohammad F, Aryal S, Ho J, Tan TL, Eisaka A, Claridge-chang A, Mohammad F, Aryal S, Ho J, Stewart JC, et al. 2016. Ancient anxiety pathways influence Drosophila ancient anxiety pathways influence Drosophila defense behaviors. Curr Biol 26: 981-986.

Morellini F, Sivukhina E, Stoenica L, Oulianova E, Bukalo O, Jakovcevski I, Dityatev A, Irintchev A, Schachner M. 2010. Improved reversal learning and working memory and enhanced reactivity to novelty in mice with enhanced GABAergic innervation in the dentate gyrus. Cereb Cortex 20: 2712-2727.

Mota T, Giurfa M. 2010. Multiple reversal olfactory learning in honeybees. Front Behav Neurosci 4: 1-9.

Muenz TS, Groh C, Maisonnasse A, Le Conte Y, Plettner E, Rössler W. 2015. Neuronal plasticity in the mushroom body calyx during adult maturation in the honeybee and possible pheromonal influences. Dev Neurobiol 75: 1368-1384.

Powell SB, Khan A, Young JW, Scott CN, Buell MR, Caldwell S, Tsan E, de Jong LA, Acheson DT, Lucero J, et al. 2015. Early adolescent emergence of reversal learning impairments in isolation-reared rats. Dev Neurscience 37: 253-262.

Ren Q, Li H, Wu Y, Ren J, Guo A. 2012. A GABAergic inhibitory neural circuit regulates visual reversal learning in Drosophila. J Neurosci 32: $11524-11538$.

Robinson GE. 1992. Regulation of division of labor in insect societies. Annu Rev Entomol 37: 637-665.

Rosenzweig MR, Bennett EL. 1996. Psychobiology of plasticity: effects of training and experience on brain and behavior. Behav Brain Res 78: 57-65.

Schaefers ATU. 2013. Rearing conditions and domestication background determine regulation of hippocampal cell proliferation and survival in adulthood - Laboratory CD1 and C57Bl/6 mice versus wild house mice. Neuroscience 228: $120-127$.

Scholl C, Wang Y, Krischke M, Mueller MJ, Amdam GV, Rössler W. 2014 Light exposure leads to reorganization of microglomeruli in the 
mushroom bodies and influences juvenile hormone levels in the honeybee. Dev Neurobiol 74: 1141-1153.

Simpson J, Kelly JP. 2011. The impact of environmental enrichment in laboratory rats-behavioural and neurochemical aspects. Behav Brain Res 222: 246-264.

Smith D, Wessnitzer J, Webb B. 2008. A model of associative learning in the mushroom body. Biol Cybern 99: 89-103.

Stieb SM, Muenz TS, Wehner R, Rössler W. 2010. Visual experience and age affect synaptic organization in the mushroom bodies of the desert ant Cataglyphis fortis. Dev Neurobiol 70: 408-423.

Strausfeld NJ, Hansen L, Li Y, Gomez RS, Ito K. 1998. Evolution, discovery, and interpretations of arthropod mushroom bodies. Learn Mem 5: 11-37.

Strube-Bloss MF, Nawrot MP, Menzel R. 2011. Mushroom body output neurons encode odor - reward associations. I Neurosci 31: 3129-3140.
Szyszka P, Galkin A, Menzel R. 2008. Associative and non-associative plasticity in kenyon cells of the honeybee mushroom body. Front Syst Neurosci 2: 3.

Withers GS, Fahrbach SE, Robinson GE. 1993. Selective neuroanatomical plasticity and division of labour in the honeybee. Nature 364: 238-240.

Wu Y, Ren Q, Li H, Guo A. 2012. The GABAergic anterior paired lateral neurons facilitate olfactory reversal learning in Drosophila. Learn Mem 19: $478-86$.

Yilmaz A, Lindenberg A, Albert S, Grübel K, Spaethe J, Rössler W, Groh C. 2016. Age-related and light-induced plasticity in opsin gene expression and in primary and secondary visual centers of the nectar-feeding ant Camponotus rufipes. Dev Neurobiol 76: 1041-1057.

Received March 7, 2017; accepted in revised form July 5, 2017. 


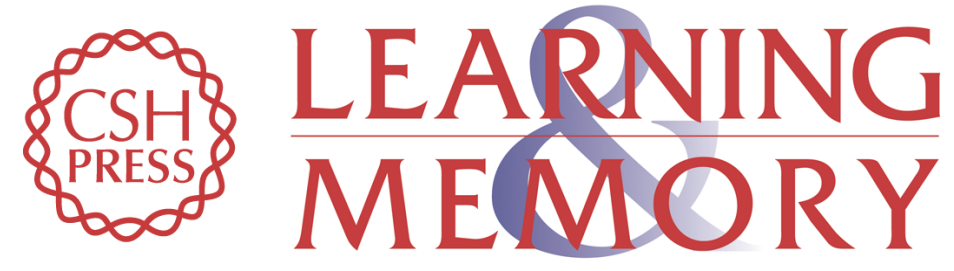

\section{Experience during early adulthood shapes the learning capacities and the number of synaptic boutons in the mushroom bodies of honey bees (Apis mellifera)}

Amélie Cabirol, Rufus Brooks, Claudia Groh, et al.

Learn. Mem. 2017, 24:

Access the most recent version at doi:10.1101/Im.045492.117

Supplemental http://learnmem.cshlp.org/content/suppl/2017/09/13/24.10.557.DC1
Material

References This article cites 59 articles, 14 of which can be accessed free at: http://learnmem.cshlp.org/content/24/10/557.full.html\#ref-list-1

Creative This article is distributed exclusively by Cold Spring Harbor Laboratory Press for the Commons first 12 months after the full-issue publication date (see License http://learnmem.cshlp.org/site/misc/terms.xhtml). After 12 months, it is available under a Creative Commons License (Attribution-NonCommercial 4.0 International), as described at http://creativecommons.org/licenses/by-nc/4.0/.

Email Alerting Receive free email alerts when new articles cite this article - sign up in the box at the Service top right corner of the article or click here. 